\title{
REVIEW
}

\section{Epigenetic regulation in diabetic vascular complications}

\author{
Jiayu Jin, Xinhong Wang, Xiuling Zhi and Dan Meng \\ Department of Physiology and Pathophysiology, School of Basic Medical Sciences, Fudan University, Shanghai, China \\ Correspondence should be addressed to X Zhi or D Meng: zhixiuling@fudan.edu.cn or dmeng@fudan.edu.cn
}

\begin{abstract}
Cardiovascular disease (CVD), the main complication of diabetes mellitus (DM), accounts for a high percentage of mortality in diabetic patients. Endothelial dysfunction is a major causative event in the pathogenesis of diabetes-related vascular disease and the earliest symptom of vascular injury. Epigenetic modification plays a key role in the initiation, maintenance, and progression of both endothelial dysfunction and diabetes. Epigenetic alterations respond to the environment and mediate the 'legacy effect' of uncontrolled hyperglycaemia early in the disease despite thorough glycaemic control in a phenomenon called metabolic memory. Therefore, an understanding of the integrated system of different epigenetic mechanisms in DM and its vascular complications is urgently needed. This review summarizes aberrant epigenetic regulation under diabetic conditions, including histone modifications, DNA methylation, and non-coding RNAs (ncRNAs). Understanding the connections between these processes and DM may reveal a novel potential therapeutic target for diabetic vascular complications.
\end{abstract}

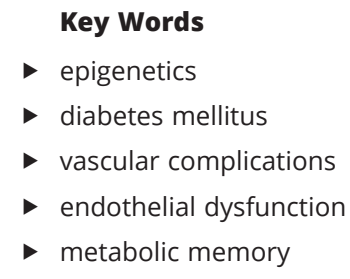

Journal of Molecular Endocrinology (2019) 63, R103-R115

\section{Introduction}

Diabetes mellitus (DM) is a metabolic disorder with significant morbidity that currently affects approximately 150 million people, and the World Health Organization (WHO) predicts that this number could double by 2050 (Lumsden et al. 2013). Diabetes is an independent risk factor for cardiovascular diseases (CVD), and the prevalence of CVD in patients with type 2 diabetes mellitus (T2DM) is 2-4 times higher than that in non-diabetic patients (Contreras et al. 2000). What's more, the diabetic vascular complications such as heart failure, peripheral arteriopathy, myocardial infarction, angina pectoris, venous and arterial thrombosis have been determined clinically in the T2DM patients. In fact, DM-derived injuries on micro- and macro-vessels are considered the main causes of increased morbidity and mortality in this disease (Wold et al. 2005, Jia et al. 2018).
Vascular endothelium is an essential metabolic organ that regulates the structure and tone of the vasculature by secreting several vasodilators (e.g., prostacyclin (PGI 2), nitric oxide (NO) and endothelial-derived hyperpolarizing factors (EDHF)) and vasoconstrictors (e.g., endothelin-1 (ET-1), thromboxane 2, angiotensin II and reactive oxidative species (ROS)) (Avogaro et al. 2011). Endothelial cells (ECs) remain in a quiescent state under normal conditions; however, the function of ECs is inhibited upon exposure to various harmful stimuli such as high glucose levels, agonists, and shear stress, which leads to the onset of endothelial dysfunction (Ghosh et al. 2017). In general, endothelial dysfunction is the underlying mechanism of diabetic vascular disease and the earliest response to vascular injury (Vita \& Keaney 2002), which is usually characterized by increased 
vasoconstriction factor secretion, decreased cell viability, elevated endothelial permeability, reduced nitric oxide production, and disordered thrombosis (Tabit et al. 2010). The high-glucose environment in diabetic patients can undermine endothelial function by diminishing highdensity lipoprotein (HDL) uptake, decreasing endothelial nitric oxide (eNOS) level, reducing nitric oxide availability, compromising VE-cadherin expression and generating mitochondrial reactive oxygen species (ROS) (Meng et al. 2012). The vasculature becomes vulnerable and enters a pro-atherogenic and pro-thrombotic state under such disorder (Vita \& Keaney 2002). In particular, early exposure to hyperglycaemia can exert a 'legacy effect' on ECs that perpetuates endothelial dysfunction even following the in-time return to improved glycaemic control, which is called 'metabolic memory' (Testa et al. 2017).

A variety of genes related to T2DM have been identified; however, the expression of these genes per se cannot precisely predict the clinical risk of T2DM, implicating the role of other factors in the pathogenesis of T2DM. In addition, the risk of T2DM increases with age (Villeneuve $\&$ Natarajan 2010). Moreover, genetically identical twins have different susceptibilities to diabetes if they grow up in different environments (Lipman \& Tiedje 2006, Tan et al. 2013). All these findings indicate that genetic predisposition is not the only factor accounting for T2DM (Vassy et al. 2012). A growing amount of evidence suggests that epigenetic mechanisms (e.g. histone modifications, DNA methylation, and non-coding (ncRNAs)) form a key interface between environmental factors and genetic predisposition, which responds to the environment and mediates the long-term effects of harmful stimuli, such as dyslipidaemia and hyperglycaemia (Keating \& El-Osta 2013). Therefore, epigenetic signals driven by the environment at least partly explain the link between early hazardous effects and the later risk of metabolic memory and sustained endothelial dysfunction.

It has been revealed that epigenetics is involved in nearly all disease progression. A great number of studies have demonstrated a crucial role for epigenetic regulatory mechanisms in cardiac homeostasis. It is evident by overt epigenetic modifications in cardiovascular anomalies including hypertension, coronary heart disease, stroke and peripheral vascular diseases in the presence of major pro-epigenetic cardiovascular risk factors such as hyperglycaemia, aging, high fat intake, and exercise. Understanding specific CVD pathologies associated with T2DM and their possible link to epigenetics will be of farreaching significance (Zhang \& Ren 2016).
This article reviews the molecular mechanisms of endothelial dysfunction and metabolic memory in DM, focusing predominantly on the underlying epigenetic mechanisms whose aberrant regulation under diabetic conditions contributes to the pathogenesis of DM and its vascular complications.

\section{Mechanisms of epigenetics regulation involved in endothelial dysfunction}

In recent years, an increasing number of studies have emphasized the link between epigenetic factors and T2DM-related CVD. Epigenetics refers to alterations in gene expression and phenotype without changes in DNA sequence, such as post-translational histone modifications, DNA methylation, and ncRNA-mediated translational control. These alterations mediate the accessibility of genes for transcription factor binding and therefore influence their expression, which is essential to a variety of biological processes (De Rosa et al. 2018). Epigenetic modification is a cell-specific process with a high degree of responsiveness to environmental stimuli that accounts for many hidden causes of diseases (De Rosa et al. 2018).

Current therapies for T2DM primarily focus on reducing its associated cardiovascular risk factors and optimizing glycaemic control, while diabetic CVD and many other irreversible complications have not been fully concerned (Pasquier et al. 2015). Addressing the epigenetic links between endothelial dysfunction and T2DM and elucidating their potential pathophysiological role in diabetic CVD will help to identify possible new targets for diabetic CVD treatment.

\section{Histone modifications}

Emerging evidence has shown that histone modifications are involved in a crucial mechanism triggered by hyperglycaemia that leads to endothelial dysfunction in diabetes. Modifications to the N-terminal amino acid residues of histones, including acetylation, phosphorylation, ubiquitination, and methylation, are essential for the presence of chronic diabetic complications (Fig. 1).

A recent study identified the glucose-AMPK-TET2$5 \mathrm{hmC}$ axis, which is involved in the epigenetic regulation of diabetes. The phosphorylation of TET2 at serine 99 mediated by AMPK is suppressed under a high-glucose milieu, leading to TET2 destabilization and thereby the dysregulation of 5-hydroxymethylcytosine (5hmC) 


\section{Stimuli}

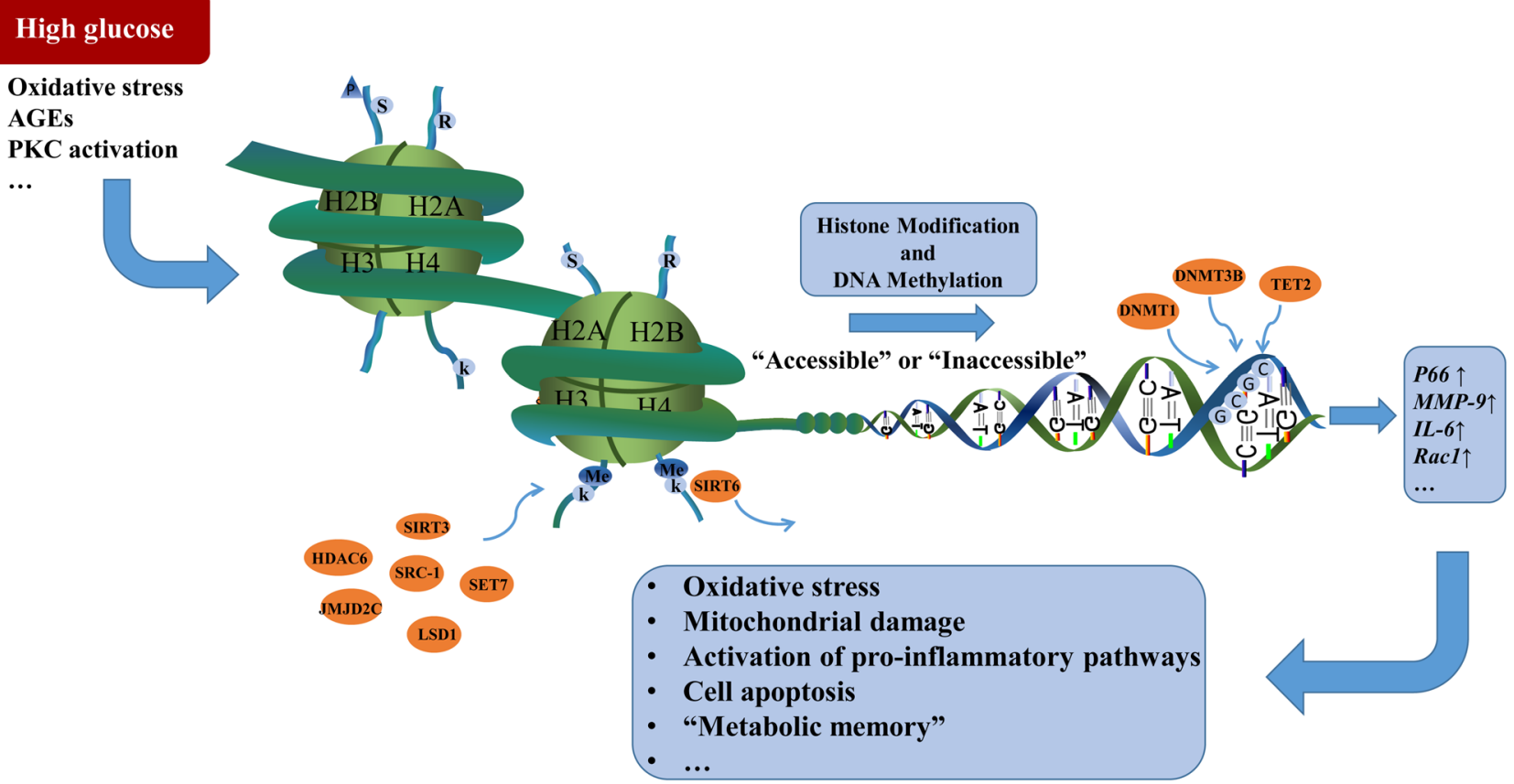

Figure 1

Aberrant epigenetic modifications associated with T2DM and its vascular complications. Stimulation under diabetic conditions can trigger aberrant epigenetic modifications by recruiting or dissociating several crucial epigenetic factors, such as Set7, HDAC6, SRC-1, JMJD2C, LSD1, making chromatin 'accessible' or 'inaccessible' for transcription factor binding and therefore influencing gene expression (e.g. P66, MMP-9, IL-6, Rac1). This series of events leads to 'metabolic memory', oxidative stress, inflammation, mitochondrial damage, and cell apoptosis, which in turn promotes chronic hyperglycaemia characteristic of T2DM and has a further effect on histone modification and DNA methylation. A full colour version of this figure is available at https://doi. org/10.1530/JME-19-0170.

in vitro and in vivo, suggesting a correlation between diabetes and cancer. Interestingly, the administration of the anti-diabetic drug metformin could rescue these events, which indicates a novel aspect for future T2DM prevention and treatment ( $\mathrm{Wu}$ et al. 2018). The activated demethylase LSD1 was found to be associated with MMP-9 activation, mitochondrial damage, and cell apoptosis in diabetes. An LSD1-induced altered H3K9 methylation pattern unwinds chromatin, making MMP-9 accessible to several transcriptional factors, such as NF-kB that promote the transcription of MMP-9 and aggravate mitochondrial damage (Mishra et al. 2016).

Other stimuli independent of glucotoxicity have also emerged as key players in the induction of epigenetic alterations (e.g. oxidative stress, AGEs, PKC activation). In particular, oxidative stress plays a causative role in the hyperacetylation of the $p 66$ Shc promoter and the concurrent repression of $\mathrm{CpG}$ methylation (Titchenell \& Antonetti 2013). Moreover, the epigenetic role of the methyltransferase SUV39H1 in oxidative stress has recently been discovered. The compromised expression of SUV39H1 in obesity promoted the recruitment of the acetyltransferase SRC-1 and the demethylase JMJD2C to the $p 66$ Shc promoter, resulting in decreased acetylation and di/trimethylation of $\mathrm{H} 3 \mathrm{~K} 9$, which culminated in the activation of mitochondrial p66 Shc and increased oxidative stress (Costantino et al. 2019). GLP-1 has a protective effect against oxidative stress in human umbilical vein endothelial cells (HUVECs) by upregulating HDAC6 in a GLP-1R-ERK1/2-dependent pathway, suggesting the protective role of HDAC6 in endothelial dysfunction induced by oxidative stress (Cai et al. 2018). Aberrant histone modifications and increased ROS were shown to be associated in human aortic endothelial cells (HAECs). The exposure of HAECs to hyperglycaemia induced methylation (H3K9me3, H3K9me2, H3K4me1) at the eNOS and NOX4 promoters and activated these two genes, which are major sources of ROS, leading to an increased risk of endothelial dysfunction and diabetic vascular complications (Liao et al. 2018).

Sirtuins, which are well-known epigenetic metabolic modulators, are also recognized for playing a specific role in regulating EC functions. SIRT6, which is known for deacetylating H3K9Ac and H3K56Ac, was downregulated 
in carotid plaques from asymptomatic diabetic patients and in the pancreas islets and retina (Zorrilla-Zubilete et al. 2018) of diabetic mice, resulting in inflammation and oxidative stress. SIRT3 is involved in antioxidant pathways and advanced glycation end product (AGE)induced EPC dysfunction and it has been demonstrated to decrease cellular ROS levels through deacetylating and activating MnSOD (Chang et al. 2017). SIRT1 was found to be suppressed by the accumulation of AGEs in human endothelial Eahy926 cells, leading to the acetylation of p53 and the apoptosis of ECs, both of which were ameliorated or decreased by Sirt1 activator (resveratrol) or inhibitor (sirtinol) (Li et al. 2015). Indeed, a great number of potential drugs with anti-diabetic and epigenetic activities named epigenetic drugs or epidrugs have been discovered, including HDAC inhibitors (e.g. phenylbutyrate), HDAC activators (e.g. resveratrol, metformin), and acetyltransferase inhibitors (e.g. curcumin), most of which are being intensely studied and may become novel therapeutic targets in diabetic vascular complications (Sommese et al. 2017).

\section{DNA methylation}

DNA methylation mainly occurs on the cytosine ring of 'CpG islands' in the 5' regulatory regions of many genes through DNA methyltransferases (DNMTs), which always results in gene silencing (Hu et al. 2017). DNA methylation is closely related to the stability of gene expression status and the integrity of the genome by recruiting chromatin remodelling complexes that modify nucleosomes (Fig. 1).

DNA methylation analysis of human pancreatic islets identified $1649 \mathrm{CpG}$ sites in 853 genes that were differentially methylated in T2DM patients compared to controls (Dayeh et al. 2013). Consistently, in a study using 84 well-matched monozygotic twin pairs, global DNA methylation was linked to higher risk of insulin resistance (IR) independent of other risk factors (Zhao et al. 2012).

Fluctuations in glucose levels are associated with DNA hypomethylation of the P66 Shc promoter, which causes a significant increase in $P 66$ level, culminating in persistent oxidative stress and endothelial dysfunction in T2DM patients (Keating et al. 2016). The expression of the PGC-1 $\alpha$ gene (PPARGC1A) is markedly reduced in T2DM patients along with a two-fold increase in DNA methylation of the CpG regions of the $P G C-1 \alpha$ promoter, which causes reduced insulin secretion (Ling et al. 2008). IL-6, a proinflammatory cytokine associated with prediabetes and vascular complications in DM (Lowe et al. 2014), was reported to alter the DNA methylation patterns of genes involved in insulin signalling by regulating the DNMT3B and DNMT1 protein expression (Balakrishnan et al. 2018). Altered DNA methylation was also found at the proximal promoter and CpG regions near intron 1 of $E d n 1$, a prominent gene encoding the endothelin-1 (ET-1) protein that is responsible for the aggravated pathologic state in several diabetic complications (Biswas et al. 2018a). Another study showed that hyperglycaemia in diabetic retinopathy could increase $5 \mathrm{hmC}$ levels, activate TET2 and facilitate the recruitment of DNMT1 at the MMP-9 promoter region, which could further activate MMP-9 and disturb retinal mitochondrial homeostasis (Kowluru \& Shan 2017). The DNA methylation-demethylation status of Rac1 has recently been associated with the regulation of oxidative stress in diabetic retinopathy. Both groups of opposing enzymes, DNMTs and TETs, are activated in diabetic retina; thus, $5 \mathrm{mC}$ levels at the promoter region of Rac1 increase due to DNMT1 activation, yet a concomitant increase in TET2 promptly hydroxymethylates it to $5 \mathrm{hmC}$, allowing NF-кB to bind and activate Rac1. Activated Rac1 then promotes ROS production via NOX2, which causes mitochondrial dysfunction and capillary cell apoptosis, ultimately resulting in diabetic retinopathy (Duraisamy et al. 2018). A recent study demonstrated crosstalk between DNA methylation and histone modification in diabetic ECs. Upregulated EZH2 alters H3K27 methylation pattern and promotes the recruitment of DNMT1-TET2 to MMP-9 promoter in human retinal endothelial cells (HRECs) in a high-glucose milieu, resulting in transcriptional activation of MMP-9, which is one of the earliest events in the pathogenesis of diabetic retinopathy (Duraisamy et al. 2017).

\section{Non-coding RNAs}

\section{Dysregulation of miRNAs}

miRNAs are a class of non-coding, single-stranded RNA molecules, approximately 22 nucleotides in length, which usually function as translational repressors. Many miRNAs have been shown to be indispensable in the pathophysiological processes of diabetic complications, including atherosclerosis, microvascular dysfunction, and retinopathy (Table 1) (McClelland \& Kantharidis 2014). MiRNAs are now considered a novel group of potential markers in prediabetes and diabetes that provide new insights into potential therapeutic targets in patients with diabetes.

Of the miRNA profiles of various ECs in hyperglycaemic conditions, ten miRNAs (miR-26b-5p, miR-26a-5p, miR-29c-3p, miR-29b-3p, miR-130b-3p, 
Table 1 MicroRNAs associated with vascular dysfunction in diabetic patients and models.

\begin{tabular}{|c|c|c|c|c|c|}
\hline miRs & Up-/down-regulation & Cell type & Target gene & Function regulated & References \\
\hline miR-26b-5p & Up & HUVEC & EphA2, PTEN, RB1, EZH2, MCL1 & $\begin{array}{l}\text { Vascular leakage, } \\
\text { angiogenesis, tumor } \\
\text { growth, apoptosis, } \\
\text { senescence }\end{array}$ & $\begin{array}{l}\text { Silambarasan } \\
\text { et al. (2016) }\end{array}$ \\
\hline $\operatorname{miR}-26 a-5 p$ & Up & HUVEC & HMGA2, PTEN, RB1, EZH2, MCL1 & $\begin{array}{l}\text { Vascular leakage, } \\
\text { angiogenesis, tumor } \\
\text { growth, apoptosis, } \\
\text { senescence }\end{array}$ & $\begin{array}{l}\text { Silambarasan } \\
\text { et al. (2016) }\end{array}$ \\
\hline miR-29c-3p & Up & HUVEC & MCL1, BCL2, HDAC4, PTEN & Angiogenesis, apoptosis & $\begin{array}{l}\text { Silambarasan } \\
\text { et al. (2016) }\end{array}$ \\
\hline miR-29b-3p & Up & HUVEC & MCL1, BCL2, VEGFA, PTEN & Angiogenesis, apoptosis & $\begin{array}{l}\text { Silambarasan } \\
\text { et al. (2016) }\end{array}$ \\
\hline miR-130b-3p & Up & HUVEC & PTEN, STAT3, PPARG & $\begin{array}{l}\text { Pathological } \\
\text { angiogenesis, tumor } \\
\text { growth, endothelial } \\
\text { activation, } \\
\text { atherogenesis }\end{array}$ & $\begin{array}{l}\text { Silambarasan } \\
\text { et al. (2016) }\end{array}$ \\
\hline miR-125b-1-3p & Up & HUVEC & S1PR1 & Endothelial dysfunction & $\begin{array}{l}\text { Silambarasan } \\
\text { et al. (2016) }\end{array}$ \\
\hline miR-192-5p & Up & HUVEC & $B C L 2, R B 1$ & Apoptosis & $\begin{array}{l}\text { Silambarasan } \\
\text { et al. (2016) }\end{array}$ \\
\hline miR-140-5p & Up & HUVEC & VEGFA, HDAC4 & $\begin{array}{l}\text { Pathological } \\
\text { angiogenesis }\end{array}$ & $\begin{array}{l}\text { Silambarasan } \\
\text { et al. (2016) }\end{array}$ \\
\hline miR-221-3p & Up & HUVEC & PTEN, RB1, PAK1 & $\begin{array}{l}\text { Angiogenesis, tumor } \\
\text { growth, apoptosis, } \\
\text { senescence, endothelial } \\
\text { barrier function }\end{array}$ & $\begin{array}{l}\text { Silambarasan } \\
\text { et al. (2016) }\end{array}$ \\
\hline miR-320a & Up & HUVEC & NRP1, MCL1 & $\begin{array}{l}\text { Endothelial tip cell } \\
\text { function, angiogenesis, } \\
\text { tumor progression }\end{array}$ & $\begin{array}{l}\text { Silambarasan } \\
\text { et al. (2016) }\end{array}$ \\
\hline miR-29 & Up & $\begin{array}{l}\text { Human dermal } \\
\text { microvascular } \\
\text { endothelial } \\
\text { cells (HMVEC) }\end{array}$ & LYPLA1 & $\begin{array}{l}\text { NO production, } \\
\text { endothelium- } \\
\text { dependent vasodilation }\end{array}$ & $\begin{array}{l}\text { Widlansky et al. } \\
\text { (2018) }\end{array}$ \\
\hline miR-34a & Up & HUVEC & SIRT1 & Oxidative stress & Li et al. (2016) \\
\hline miR-126 & Up & HUVECS & Tissue factor & $\begin{array}{l}\text { Anti-thrombotic, } \\
\text { anti-inflammatory, } \\
\text { endothelial } \\
\text { homeostasis, vascular } \\
\text { integrity }\end{array}$ & $\begin{array}{l}\text { Zampetaki } \\
\text { et al. (2010), } \\
\text { Witkowski } \\
\text { et al. (2018) }\end{array}$ \\
\hline miR-19a & Up & HMECS & VCAM & $\begin{array}{l}\text { Anti-thrombotic, } \\
\text { anti-inflammatory, }\end{array}$ & $\begin{array}{l}\text { Witkowski et al. } \\
\text { (2018) }\end{array}$ \\
\hline miR-342-3p & Down & HUVECS & FGF11 & Angiogenesis & $\begin{array}{l}\text { Cheng et al. } \\
\text { (2018) }\end{array}$ \\
\hline miR-483-3p & Up & $\mathrm{H} 9 \mathrm{c} 2$ & IGF1 & Apoptosis & $\begin{array}{l}\text { Qiao et al. } \\
\text { (2016) }\end{array}$ \\
\hline miR-200b & Up & HMECS & Ets-1, VEGF & Angiogenesis. & $\begin{array}{l}\text { Chan et al. } \\
\text { (2011) }\end{array}$ \\
\hline miR-221 & Up & HUVECS & c-kit & $\begin{array}{l}\text { c-kit expression and } \\
\text { migration of HUVECs }\end{array}$ & $\begin{array}{l}\text { Bridgeman et al. } \\
\text { (2018) }\end{array}$ \\
\hline miR-222 & Up & VSMCS & p27Kip1 & Intimal thickening & $\begin{array}{l}\text { Bridgeman et al. } \\
\text { (2018) }\end{array}$ \\
\hline
\end{tabular}

miR-125b-1-3p, miR-192-5p, miR-140-5p, miR-221-3p and miR-320a) were steadily upregulated with increasing glucose concentration. Four miRNAs (miR-130b-3p, miR-26a-5p, miR-221-3p, and miR-140-5p) were 'glucoseresponsive miRNAs' that were positively related to endogenous glucose levels, and three of these miRNAs
(miR-140-5p, miR-221-3p and miR-130b-3p) could lead to the onset of endothelial dysfunction by targeting several genes associated with apoptosis, inflammation, hyperpermeability, senescence, and pathological angiogenesis (Silambarasan et al. 2016). Consistently, miR-29 plays a key role in promoting NO production, 
restoring endothelium-dependent vasodilation and maintaining endothelial function in diabetic conditions by the downregulation of lysophospholipase I (LYPLA1), a critical protein that is capable of reducing NO production through depalmitoylating eNOS (Widlansky et al. 2018). The expression of endothelial miR-34a can be induced by the cooperation of p53 and P66 Shc in a redox-dependent fashion upon the exposure of miR-34a to hyperlipidaemia and hyperglycaemia in DM, which leads to diabetic endothelial dysfunction through an oxidant-sensitive mechanism that targets SIRT1 (Li et al. 2016). MiR-126 was highly expressed under normal conditions but downregulated under high-glucose conditions in endothelial apoptotic bodies, suggesting the close relationship between miR-126 and peripheral artery disease in DM patients (Zampetaki et al. 2010). MiR-126 can also cooperate with miR-19a to exert antithrombotic and anti-inflammatory effects on ECs by regulating the expression of vascular tissue factor in DM patients (Witkowski et al. 2018). The expression of miR-342-3p was compromised in the ECs of T2DM mice, while the augmentation of miR-342-3p levels exerted proangiogenic activity by activating FGF11 signalling at post-transcriptional level (Cheng et al. 2018). MiR483-3p was shown to be involved in many biological processes, and the increased expression of miR-483-3p in the vasculature of diabetic subjects had a causative role in impaired endothelial regeneration. Moreover, miR483-3p downregulates the IGF1 gene, thereby triggering the apoptosis of ECs in diabetes (Qiao et al. 2016). Hyperglycaemia can aggravate endothelial dysfunction by reducing methylation of the miR-200b promoter, leading to a pathologic increase of miR-200b and thus driving diabetic vasculopathy (Chan et al. 2011, Singh et al. 2017). An inspiring finding suggested that metformin is capable of rescuing endothelial dysfunction in patients with diabetes through regulating several critical miRNAs, including let-7 family miRNAs, miR-221, miR-222, and miR-34a, which are associated with vascular dysfunction in diabetic patients (Bridgeman et al. 2018). Moreover, the metformin-induced activation of DICER, a central enzyme involved in miRNA processing, may also explain why metformin administration can rescue endothelial dysfunction (Noren Hooten et al. 2016).

\section{Circular RNAs}

Circular RNAs (cirRNAs) are a subclass of closed circular ncRNAs that do not have a $3^{\prime}$ polyadenylated tail or 5' cap and form a loop structure with covalent bonds.
cirRNAs mainly comprise primary RNA transcripts from an intron or an exon or the back-splicing of both introns and exons (Tang et al. 2018). The biological functions of cirRNAs mainly lie in the six activities: (1) interaction with mRNAs, (2) interaction with lncRNAs, (3) transcriptional regulation, (4) miRNA sponge activity, (5) Ramie/Hemp Bath sponge activity, (6) secretion into exosomes (Zhao et al. 2016). cirRNAs have been shown to play an increasingly important role in cell mobility, proliferation, differentiation and apoptosis (Legnini et al. 2017). Furthermore, cirRNAs are crucial regulators of the pathogenesis of several metabolic diseases such as DM and are associated with the transcriptional and posttranscriptional regulation of endothelial dysfunction under high-glucose conditions (Stoll et al. 2018).

cirRNA microarray profiling in human ECs showed a total of 95 differentially expressed cirRNAs in human ECs under hyperglycaemic conditions, which confirmed the important regulatory role of cirRNAs in diabetes (Shang et al. 2018). In particular, a variety of miRNAs that interact with these differentially expressed cirRNAs were identified, including miR-3202, miR-1273g-3p, and miR-657, all of which have been demonstrated vital in regulating biological functions of high glucose-cultured ECs (Huang et al. 2017).

The cirRNA-miRNA-mRNA interaction network is involved in the pathophysiology of diabetic endothelial dysfunction (Table 2). The cirRNA cPWWP2A functions as an endogenous miR-579 sponge to sequester miR-579 activity that upregulated SIRT1, occludin, and angiopoietin and exacerbated diabetes-induced retinal endothelial dysfunction (Liu et al. 2019). Aberrant cPWWP2A expression can also attenuate pericyte-EC crosstalk, leading to vascular obliteration, leakage, and pathological angiogenesis (Boeckel et al. 2015). The upregulated expression of cirRNA-cZNF609, which promotes endothelial migration and tube formation by sponging miR-615-5p and promoting the transcription of the miR-615-5p target gene, myocyte-specific enhancer factor 2A (MEF2A), was shown in diabetic retinal endothelial cells (RECs) (Liu et al. 2017). cirRNA-0054633 exhibits protective effects against diabetic endothelial dysfunction in HUVECs through a similar mechanism via inactivating miR-218, thereby changing the expression levels of ROBO1 and HO-1, which contributes to EC migration, proliferation and angiogenesis (Pan et al. 2018). Changes in circHIPK3 levels have been detected in HAECs and HUVECs. The hyperglycaemia-induced inactivation of circHIPK3 upregulates miR-124, resulting in decreased levels of its potential pro-survival targets (STAT3 and 

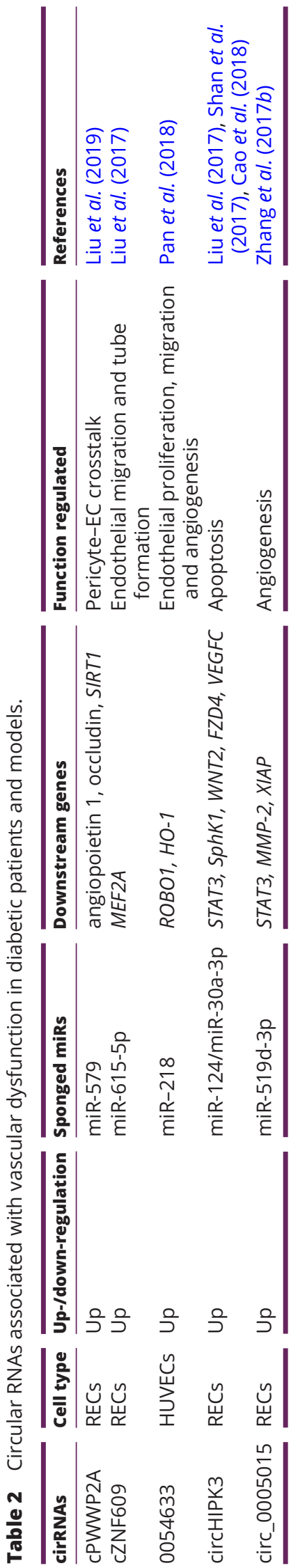

https://jme.bioscientifica.com
SPHK1), which finally triggers apoptosis in ECs (Cao et al. 2018). Another eight miRNAs (miR-654, miR-584, miR-338, miR-29b, miR-152, miR-29a, miR-193a, and miR-379) were found to be potential targets of circHIPK3 (Liu et al. 2017). CircHIPK3 was found to sponge and suppress miR-30a-3p, thereby activating WNT2, FZD4, and VEGFC and exerting its protective effect against endothelial dysfunction under high-glucose conditions (Shan et al. 2017). Furthermore, circ_0005015 can function as a sink for miR-519d-3p to abrogate the repressive effect of miR-519d-3p on XIAP, STAT3, and MMP-2, indicating its potential protective role in endothelial angiogenic function (Zhang et al. 2017b). CirRNAs may also serve as transcriptional regulators that mediate chromatin remodelling by binding to RNA-binding proteins (RBPs) such as EIF4A3, FUS and HUR in promoter regions of the host gene (Zhang et al. 2017b).

\section{Long non-coding RNAs}

Long non-coding RNAs (lncRNAs), the non-coding transcripts more than 200 nucleotides in length (Sun \& Wong 2016), have been identified as key epigenetic regulators that participate in a variety of biological processes by guiding certain histone-modifying complexes, promoting the association between enhancers and promoters through chromosomal looping, acting as molecular sponges, and serving as scaffolds for specific molecules (Biswas et al. 2018b).

Emerging evidence has authenticated the contributions of various lncRNAs to the biological functions of ECs (Table 3) (Goyal et al. 2018). In a systematic transcriptional study conducted to screen lncRNAs in response to the exposure of HUVECs to high-glucose conditions, 100 of the 30586 lncRNAs were appreciably upregulated, while 186 were significantly downregulated, which provided novel insights into the potential regulatory mechanism of hyperglycaemia-associated endothelial dysfunction (Singh et al. 2016).

MALAT1, an upregulated IncRNA in the retinas of diabetic rats, is enriched in ECs and regulates many endothelial functions such as migration, proliferation, and tube formation in a p38 MAPK-dependent manner (Liu et al. 2014). MALAT1 has also been shown to protect the endothelium from ox-LDL-induced endothelial dysfunction via downregulating miR-22-3p and upregulating CXCR2 (Tang et al. 2015). Moreover, MALAT1 can regulate DNA methylation by interacting with methyl-CpG binding protein 2 (MECP2) and thus maintain the dynamic glucose equilibrium (He et al. 2017). 
Table 3 LncRNAs associated with vascular dysfunction in diabetic patients and models.

\begin{tabular}{|c|c|c|c|}
\hline IncRNAs & Cell type & Up-/down-regulation & Targets \\
\hline MALAT1 & RECS & Up & miR-22-3p, MeCP2 \\
\hline MEG3 & RECS & Down & $T G F-\beta 1, V E G F$ \\
\hline ANRIL & HRECS & Up & p300, EZH2 \\
\hline MIAT & ECs & Up & miR-150-5p \\
\hline
\end{tabular}

In addition, the knockdown of MALAT1 in diabetic mice ameliorated retinal inflammation, and MALAT1 repression in RECs inhibited cell migration, proliferation, and tube formation (Liu et al. 2014). Thus, the inhibition of MALAT1 is a potential target for anti-angiogenic therapy.

The lncRNA MEG3 is also related to the pathogenesis of endothelial dysfunction and microvascular dysfunction. This IncRNA is hypermethylated and downregulated upon the exposure of ECs to high glucose and oxidative stress as well as in the retinas of STZ-induced diabetic mice (Qiu et al. 2016). MEG3 knockdown aggravated vascular leakage, increased inflammatory protein levels and triggered acellular capillary formation in vivo and promoted cell migration, viability, proliferation and tube formation in vitro via activating the PI3K/AKT signalling pathway (Qiu et al. 2016). In addition, the suppression of MEG3 expression was linked with compromised glucose tolerance and impaired insulin secretion (You et al. 2016). Correspondingly, the overexpression of MEG3 has been demonstrated to ameliorate diabetic retinopathy by inhibiting the expression of TGF- $\beta 1$ and VEGF (Zhang et al. 2018), which suggests the upregulation of the lncRNA MEG3 as a promising therapy for endothelial dysfunction and diabetic vascular complications.

Antisense ncRNA in the INK4 locus (ANRIL), a crucial functional lncRNA that participates in multiple human diseases, is also upregulated under hyperglycaemic conditions in diabetic subjects. Emerging evidence has revealed that ANRIL facilitates the expression of vascular endothelial growth factor (VEGF), a crucial inducer of angiogenesis, via interacting directly with P300 and EZH2 of the PRC2 complex in HRECs (Thomas et al. 2017). Consistently, ANRIL knockdown in STZ-induced diabetic mice reversed the hyperglycaemia-induced upregulation of P300 and downregulation of miR-200b and abrogated the increase in VEGF (Thomas et al. 2017). In addition to its participation in REC functions, ANRIL also plays a role in other ECs, suggesting its physiological relevance in various vascular diseases such as hypertension and atherosclerosis

\section{unction regulated}

Migration, proliferation, and tube

formation

Migration, viability, proliferation and tube formation

Angiogenesis

Vascular leakage, inflammation and neo-vascularization

\section{References}

Paneni et al. (2015)

Qiu et al. (2016), You et al. (2016), Zhang et al. (2018)

Congrains et al. (2013), Thomas et al. (2017), Zhang et al. (2017a)

Michalik et al. (2014), Paneni et al. (2013), Yan et al. (2015)
(Congrains et al. 2013). ANRIL also upregulated VEGF and contributed to angiogenesis through activating NF- $\mathrm{B}$ signalling pathway in rats with DM (Zhang et al. 2017a).

The IncRNA myocardial infarction-associated transcript (MIAT), which is enriched in ECs, has also been shown to regulate EC function and pathological angiogenesis (Michalik et al. 2014). This lncRNA was found to be upregulated in response to hyperglycaemia and in the pathological processes of some diseases associated with endothelial dysfunction (Huo et al. 2019). Consistently, siRNA-mediated knockdown of MIAT in STZ-induced diabetic mice ameliorated vascular leakage, inflammation, and neo-vascularization (Paneni et al. 2013). Crosstalk among MIAT, miR-150-5p, and VEGF mRNA has also been proposed. MIAT functions as a competing endogenous RNA (ceRNA) that acts as a molecular sponge for miR-150-5p and abrogates the inhibitory effect of miR-150-5p in RECs during pathological angiogenesis, thereby activating VEGF, the target gene of miR-150-5p (Yan et al. 2015).

\section{Epigenetic mechanisms involved in metabolic memory}

The metabolic memory phenomenon in diabetic dogs was originally observed in 1987 by Engerman and Kern to describe the deleterious 'legacy effect' of uncontrolled hyperglycaemia early in diabetes despite thorough glycaemic control (Misra \& Bloomgarden 2018). The metabolic memory phenomenon has been duplicated in both in vivo and in vitro studies. Cell culture studies have confirmed metabolic memory in RECs with persistently increased fibronectin levels, continuous oxidative stress, accelerated apoptosis and the aberrant expression of inflammatory genes despite the normalization of glucose levels, indicating that self-perpetuating varieties of genes have been induced by hyperglycaemia (Zhong \& Kowluru 2013). In some clinical trials, such as the landmark Diabetes Control and Complications Trial (DCCT) and 
Epidemiology of Diabetes Intervention and Complications (EDIC) study, tight glycaemic control for 3-5 years was not able to decrease diabetic macrovascular complications. Moreover, metabolic memory has also been confirmed in animal models of diabetic vascular complications such as diabetic retinopathy and microvascular dysfunction (Kowluru 2017).

Metabolic memory has long remained a main obstruction to the effective treatment of diabetic complications. Recently, the importance of epigenetic mechanisms in the long-term effects of hyperglycaemia on the vasculature has been increasingly appreciated. Persistent epigenetic changes can reflect metabolic history, which has been demonstrated in various experimental models including the retinas of diabetic rats in highglucose conditions (Tewari et al. 2012), zebrafish with hyperglycaemia (Olsen et al. 2012), and diabetic patientderived fibroblasts (Park et al. 2014). Changes in miRNA and histone methylation at the post-transcriptional level have also been observed after transient exposure to high-glucose conditions, indicating that geneenvironment interactions associated with epigenetic changes are closely related to the long-term deleterious effects of metabolic memory (Reddy et al. 2015). Genomewide changes, such as methylated $\mathrm{CpG}$ islands and hyperacetylation signatures, are also mediated in primary human vascular cells by elevated glucose levels that trigger the 'legacy effect' through activating several genes related to the physiopathology of diabetes, including C-C motif chemokine 2 (CCL2), interleukin-8 (IL8), matrix metalloproteinase-10 (MMP10), and cystine/glutamate transporter (SLC7A11) (Pirola et al. 2011).

Hyperglycaemia-induced increased oxidative stress in the vasculature, which is characterized by a damaged cellular antioxidant defence system characterized by the excessive production of ROS, is a central feature of endothelial dysfunction in diabetes mellitus and its associated complications (Cai \& Harrison 2000). An increasing number of studies have demonstrated that excessive ROS-mediated metabolic memory contributes to an inflammatory environment and endothelial dysfunction in the aorta (Paneni et al. 2012). Interestingly, abnormal histone modifications at the promoters of several genes associated with ROS production after transient hyperglycaemia were recently revealed. For example, hyperglycaemia reduced H3K4me1 and H3K4me2 at SOD2, which encodes MnSOD, by promoting the recruitment of SP1 and LSD1 to the SOD2 promoter in ECs. However, the methylation status had not improved three months after glucose normalization, which caused mitochondrial damage and excessive production of ROS, suggesting the critical role of histone methylation in the development of diabetic retinopathy as well as metabolic memory (Zhong \& Kowluru 2013). Moreover, SET7 and LSD1 have emerged as key influencing factors in metabolic memory via their regulation of H3K4me1, thus attenuating endothelial dysfunction induced by metabolic memory (Liao et al. 2018).

Another factor involved in metabolic memory is the sustained pro-inflammatory phenotype of diabetic ECs. Although the mechanism of this involvement is not completely clear, epigenetic modifications seem to act as a key bond connecting environmental and genetic factors that explain metabolic memory (Rana et al. 2012). The histone demethylase LSD1 was increasingly recruited to the promoter of NF-kB-p65 in response to transient hyperglycaemia in ECs, leading to decreased H3K9 and increased H3K4 methylation, which activated

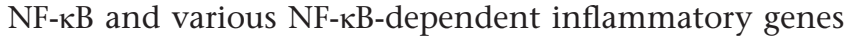
such as MCP-1 and VCAM-1. Moreover, some other hyperglycaemia-induced epigenetic alterations to the promoter of NF-kB in ECs have been revealed; these modifications include the histone acetyltransferase (HAT)mediated hyperacetylation of H3K9 and the histone methyltransferase SET7-mediated monomethylation of H3K4 (Brasacchio et al. 2009), which elevate NF-kB subunit p65 levels. On account of these events, proinflammatory pathways were activated, culminating in endothelial dysfunction. Furthermore, the repression of HAT (Cordero-Herrera et al. 2017) and Set7 (Paneni et al. 2015) was shown to abrogate NF-kB-dependent inflammatory and oxidant signalling by reverting adverse epigenetic remodelling. Therefore, the increased activity and expression of NF- $\mathrm{kB}$ in metabolic memory is a therapeutic target.

Nonenzymatic protein glycosylation in which the Maillard reaction leads to the formation of advanced glycation end products (AGEs) is another pathogenic event in metabolic memory (Yamagishi et al. 2017). Increased levels of AGEs have various detrimental effects on ECs through the binding of AGEs to the AGE receptors (RAGEs) on cell surface, which further enhances oxidative stress, decreases endothelial NO synthase, increases vascular oxidized low-density lipoprotein (LDL) deposition and attenuates inflammatory response, triggering various microvascular and macrovascular complications in DM (Stirban et al. 2014). Furthermore, the cytotoxicity of AGEs persists after being transferred to new medium without AGEs, indicating the potential role of epigenetic alterations, at least to some extent, 
in AGE-mediated metabolic memory (Ravelojaona et al. 2007).

Epigenetic changes have therefore been proposed to be involved in the mechanism of the abovementioned components of metabolic memory (oxidative stress, an inflammatory phenotype, and nonenzymatic protein glycation), which may account for the longterm detrimental effects of metabolic memory (Testa et al. 2017).

\section{Prospects}

The evidence discussed above suggests that epigenetic factors have a crucial function in the pathophysiological process of diabetes and its vascular complications. However, there is a long way to go for the clinical application of epigenetics in diabetes and its vascular complications, and further cohort studies in diabetic patients with different complications are needed to validate these results. The present diabetic parameters are not sufficient to predict the development of long-term complications of T2DM. However, with the rapid development of bioinformatics analysis platforms and high-throughput sequencing, epigenetic factors are showing more potential acting as new non-invasive biomarkers, which enables the early diagnosis of prediabetes and T2DM. Hence, it is a profound understanding of individual epigenetic landscape, genetic variability, intercellular communication mechanisms, chromatin architecture and concrete mechanisms by which histone modifications, DNA methylation, and ncRNAs interact that will contribute to the identification of diagnostic biomarkers and the design of specific molecules to regulate epigenetic markers and modulate chromatin accessibility. Moreover, future study to determine whether and how high glucose-induced epigenetic changes take part in endothelial dysfunction and their effects on inflammatory responses and oxidative stress is merited. Further study in this field will advance personalized therapeutic interventions and individualized risk assessment in diabetic patients.

\section{Declaration of interest}

The authors declare that there is no conflict of interest that could be perceived as prejudicing the impartiality of the research reported.

\section{Funding}

This work was supported by Great Program (91639103 to D M) and General Programs ( 81670450 and 81873469 to D M, 81572713 to X Z and 81873536 to $X$ W) of the National Natural Science Foundation of China and the Shanghai Municipal Health Bureau Grant of China (201640074 to D M).

\section{Author contribution statement}

J J drafted and wrote the manuscript. J J and X W collected the literature. $X Z$ and D M conceived and organized the work, and revised the manuscript.

\section{References}

Avogaro A, Albiero M, Menegazzo L, De Kreutzenberg S \& Fadini GP 2011 Endothelial dysfunction in diabetes: the role of reparatory mechanisms. Diabetes Care 34 (Supplement 2) S285-S290. (https:// doi.org/10.2337/dc11-s239)

Balakrishnan A, Guruprasad KP, Satyamoorthy K \& Joshi MB 2018 Interleukin-6 determines protein stabilization of DNA methyltransferases and alters DNA promoter methylation of genes associated with insulin signaling and angiogenesis. Laboratory Investigation 98 1143-1158. (https://doi.org/10.1038/s41374-0180079-7)

Biswas S, Feng B, Thomas A, Chen S, Aref-Eshghi E, Sadikovic B \& Chakrabarti S 2018a Endothelin-1 regulation is entangled in a complex web of epigenetic mechanisms in diabetes. Physiological Research 67 S115-S125. (https://doi.org/10.33549/physiolres.933836)

Biswas S, Thomas AA \& Chakrabarti S $2018 b$ LncRNAs: proverbial genomic 'junk' or key epigenetic regulators during cardiac fibrosis in diabetes? Frontiers in Cardiovascular Medicine 5 28. (https://doi. org/10.3389/fcrm.2018.00028)

Boeckel JN, Jaé N, Heumüller AW, Chen W, Boon RA, Stellos K, Zeiher AM, John D, Uchida S \& Dimmeler S 2015 Identification and characterization of hypoxia-regulated endothelial circular RNA. Circulation Research 117 884-890. (https://doi.org/10.1161/ CIRCRESAHA.115.306319)

Brasacchio D, Okabe J, Tikellis C, Balcerczyk A, George P, Baker EK, Calkin AC, Brownlee M, Cooper ME \& El-Osta A 2009 Hyperglycemia induces a dynamic cooperativity of histone methylase and demethylase enzymes associated with gene-activating epigenetic marks that coexist on the lysine tail. Diabetes $\mathbf{5 8}$ 1229-1236. (https://doi.org/10.2337/db08-1666)

Bridgeman SC, Ellison GC, Melton PE, Newsholme P \& Mamotte CDS 2018 Epigenetic effects of metformin: from molecular mechanisms to clinical implications. Diabetes, Obesity and Metabolism 20 1553-1562. (https://doi.org/10.1111/dom.13262)

Cai H \& Harrison DG 2000 Endothelial dysfunction in cardiovascular diseases: the role of oxidant stress. Circulation Research $\mathbf{8 7} 840-844$. (https://doi.org/10.1161/01.res.87.10.840)

Cai X, She M, Xu M, Chen H, Li J, Chen X, Zheng D, Liu J, Chen S, Zhu J, et al. 2018 GLP-1 treatment protects endothelial cells from oxidative stress-induced autophagy and endothelial dysfunction. International Journal of Biological Sciences 14 1696-1708. (https://doi. org/10.7150/ijbs.27774)

Cao Y, Yuan G, Zhang Y \& Lu R 2018 High glucose-induced circHIPK3 downregulation mediates endothelial cell injury. Biochemical and Biophysical Research Communications 507 362-368. (https://doi. org/10.1016/j.bbrc.2018.11.041)

Chan YC, Khanna S, Roy S \& Sen CK 2011 miR-200b targets Ets-1 and is down-regulated by hypoxia to induce angiogenic response of endothelial cells. Journal of Biological Chemistry 286 2047-2056. (https://doi.org/10.1074/jbc.M110.158790)

Chang M, Zhang B, Tian Y, Hu M, Zhang G, Di Z, Wang X, Liu Z, Gu N \& Liu Y 2017 AGEs decreased SIRT3 expression and SIRT3 activation protected AGEs-induced EPCs' dysfunction and strengthened antioxidant capacity. Inflammation 40 473-485. (https://doi.org/10.1007/ s10753-016-0493-1) 
Cheng S, Cui Y, Fan L, Mu X \& Hua Y 2018 T2DM inhibition of endothelial miR-342-3p facilitates angiogenic dysfunction via repression of FGF11 signaling. Biochemical and Biophysical Research Communications 503 71-78. (https://doi.org/10.1016/j. bbrc.2018.05.179)

Congrains A, Kamide K, Ohishi M \& Rakugi H 2013 ANRIL: molecular mechanisms and implications in human health. International Journal of Molecular Sciences 14 1278-1292. (https://doi.org/10.3390/ ijms14011278)

Contreras F, Rivera M, Vasquez J, De La Parte MA \& Velasco M 2000 Diabetes and hypertension physiopathology and therapeutics. Journal of Human Hypertension 14 (Supplement 1) S26-S31. (https:// doi.org/10.1038/sj.jhh.1000983)

Cordero-Herrera I, Chen X, Ramos S \& Devaraj S 2017 (-)-Epicatechin attenuates high-glucose-induced inflammation by epigenetic modulation in human monocytes. European Journal of Nutrition 56 1369-1373. (https://doi.org/10.1007/s00394-015-1136-2)

Costantino S, Paneni F, Virdis A, Hussain S, Mohammed SA, Capretti G, Akhmedov A, Dalgaard K, Chiandotto S, Pospisilik JA, et al. 2019 Interplay among H3K9-editing enzymes SUV39H1, JMJD2C and SRC-1 drives p66Shc transcription and vascular oxidative stress in obesity. European Heart Journal 40 383-391. (https://doi.org/10.1093/ eurheartj/ehx615)

Dayeh TA, Olsson AH, Volkov P, Almgren P, Ronn T \& Ling C 2013 Identification of CpG-SNPs associated with type 2 diabetes and differential DNA methylation in human pancreatic islets. Diabetologia 56 1036-1046. (https://doi.org/10.1007/s00125-0122815-7)

De Rosa S, Arcidiacono B, Chiefari E, Brunetti A, Indolfi C \& Foti DP 2018 Type 2 diabetes mellitus and cardiovascular disease: genetic and epigenetic links. Frontiers in Endocrinology 9 2. (https://doi. org/10.3389/fendo.2018.00002)

Duraisamy AJ, Mishra M \& Kowluru RA 2017 Crosstalk between histone and DNA methylation in regulation of retinal matrix metalloproteinase-9 in diabetes. Investigative Ophthalmology and Visual Science 58 6440-6448. (https://doi.org/10.1167/iovs.17-22706)

Duraisamy AJ, Mishra M, Kowluru A \& Kowluru RA 2018 Epigenetics and regulation of oxidative stress in diabetic retinopathy. Investigative Ophthalmology and Visual Science 59 4831-4840. (https:// doi.org/10.1167/iovs.18-24548)

Ghosh A, Gao L, Thakur A, Siu PM \& Lai CWK 2017 Role of free fatty acids in endothelial dysfunction. Journal of Biomedical Science 2450. (https://doi.org/10.1186/s12929-017-0357-5)

Goyal N, Kesharwani D \& Datta M 2018 Lnc-ing non-coding RNAs with metabolism and diabetes: roles of lncRNAs. Cellular and Molecular Life Sciences 75 1827-1837. (https://doi.org/10.1007/s00018-0182760-9)

He X, Ou C, Xiao Y, Han Q, Li H \& Zhou S 2017 LncRNAs: key players and novel insights into diabetes mellitus. Oncotarget 8 71325-71341. (https://doi.org/10.18632/oncotarget.19921)

Hu X, Bai T, Xu Z, Liu Q, Zheng Y \& Cai L 2017 Pathophysiological fundamentals of diabetic cardiomyopathy. Comprehensive Physiology $\mathbf{7}$ 693-711. (https://doi.org/10.1002/cphy.c160021)

Huang X, Xie H, Xue G, Ye M \& Zhang L 2017 MiR-3202 - promoted H5V cell apoptosis by directly targeting Fas apoptotic inhibitory molecule 2 (FAIM2) in high glucose condition. Medical Science Monitor 23 975-983. (https://doi.org/10.12659/msm.899443)

Huo W, Hou Y, Li Y \& Li H 2019 Downregulated lncRNA-MIAT confers protection against erectile dysfunction by downregulating lipoprotein lipase via activation of miR-328a-5p in diabetic rats. Biochimica et Biophysica Acta: Molecular Basis of Disease 1865 1226-1240. (https://doi.org/10.1016/j.bbadis.2019.01.018)

Jia G, Hill MA \& Sowers JR 2018 Diabetic cardiomyopathy: an update of mechanisms contributing to this clinical entity. Circulation Research 122 624-638. (https://doi.org/10.1161/CIRCRESAHA.117.311586)
Keating ST \& El-Osta A 2013 Epigenetic changes in diabetes. Clinical Genetics 84 1-10. (https://doi.org/10.1111/cge.12121)

Keating ST, Plutzky J \& El-Osta A 2016 Epigenetic changes in diabetes and cardiovascular risk. Circulation Research 118 1706-1722. (https:// doi.org/10.1161/CIRCRESAHA.116.306819)

Kowluru RA 2017 Diabetic retinopathy, metabolic memory and epigenetic modifications. Vision Research 139 30-38. (https://doi. org/10.1016/j.visres.2017.02.011)

Kowluru RA \& Shan Y 2017 Role of oxidative stress in epigenetic modification of MMP-9 promoter in the development of diabetic retinopathy. Graefe's Archive for Clinical and Experimental Ophthalmology 255 955-962. (https://doi.org/10.1007/s00417-0173594-0)

Legnini I, Di Timoteo G, Rossi F, Morlando M, Briganti F, Sthandier O, Fatica A, Santini T, Andronache A, Wade M, et al. 2017 Circ-ZNF609 is a circular RNA that can be translated and functions in myogenesis. Molecular Cell 66 22.e9-37.e9. (https://doi.org/10.1016/j. molcel.2017.02.017)

Li P, Zhang L, Zhou C, Lin N \& Liu A 2015 Sirt 1 activator inhibits the AGE-induced apoptosis and p53 acetylation in human vascular endothelial cells. Journal of Toxicological Sciences 40 615-624. (https:// doi.org/10.2131/jts.40.615)

Li Q, Kim YR, Vikram A, Kumar S, Kassan M, Gabani M, Lee SK, Jacobs JS \& Irani K 2016 P66Shc-induced MicroRNA-34a causes diabetic endothelial dysfunction by downregulating Sirtuin1. Arteriosclerosis, Thrombosis, and Vascular Biology 36 2394-2403. (https://doi.org/10.1161/ATVBAHA.116.308321)

Liao Y, Gou L, Chen L, Zhong X, Zhang D, Zhu H, Lu X, Zeng T, Deng X \& Li Y 2018 NADPH oxidase 4 and endothelial nitric oxide synthase contribute to endothelial dysfunction mediated by histone methylations in metabolic memory. Free Radical Biology and Medicine 115 383-394. (https://doi.org/10.1016/j.freeradbiomed.2017.12.017)

Ling C, Del Guerra S, Lupi R, Ronn T, Granhall C, Luthman H, Masiello P, Marchetti P, Groop L \& Del Prato S 2008 Epigenetic regulation of PPARGC1A in human type 2 diabetic islets and effect on insulin secretion. Diabetologia 51 615-622. (https://doi org/10.1007/s00125-007-0916-5)

Lipman T \& Tiedje LB 2006 Epigenetic differences arise During the lifetime of monozygotic twins. MCN, the American Journal of Maternal/Child Nursing 31 204. (https://doi.org/10.1097/00005721200605000-00016)

Liu JY, Yao J, Li XM, Song YC, Wang XQ, Li YJ, Yan B \& Jiang Q 2014 Pathogenic role of lncRNA-MALAT1 in endothelial cell dysfunction in diabetes mellitus. Cell Death and Disease 5 e1506. (https://doi. org/10.1038/cddis.2014.466)

Liu C, Yao MD, Li CP, Shan K, Yang H, Wang JJ, Liu B, Li XM, Yao J, Jiang Q, et al. 2017 Silencing of circular RNA-ZNF609 ameliorates vascular endothelial dysfunction. Theranostics 7 2863-2877. (https:// doi.org/10.7150/thno.19353)

Liu C, Ge HM, Liu BH, Dong R, Shan K, Chen X, Yao MD, Li XM, Yao J, Zhou RM, et al. 2019 Targeting pericyte-endothelial cell crosstalk by circular RNA-cPWWP2A inhibition aggravates diabetes-induced microvascular dysfunction. PNAS 116 7455-7464. (https://doi. org/10.1073/pnas.1814874116)

Lowe G, Woodward M, Hillis G, Rumley A, Li Q, Harrap S, Marre M, Hamet P, Patel A, Poulter N, et al. 2014 Circulating inflammatory markers and the risk of vascular complications and mortality in people with type 2 diabetes and cardiovascular disease or risk factors: the ADVANCE study. Diabetes 63 1115-1123. (https://doi. org/10.2337/db12-1625)

Lumsden NG, Andrews KL, Bobadilla M, Moore XL, Sampson AK, Shaw JA, Mizrahi J, Kaye DM, Dart AM \& Chin-Dusting JP 2013 Endothelial dysfunction in patients with type 2 diabetes post acute coronary syndrome. Diabetes and Vascular Disease Research $10368-$ 374. (https://doi.org/10.1177/1479164113482593) (c) 2019 Society for Endocrinology Published by Bioscientifica Ltd. Printed in Great Britain 
Mcclelland AD \& Kantharidis P 2014 MicroRNA in the development of diabetic complications. Clinical Science 126 95-110. (https://doi. org/10.1042/CS20130079)

Meng D, Mei A, Liu J, Kang X, Shi X, Qian R \& Chen S 2012 NADPH oxidase 4 mediates insulin-stimulated HIF-1alpha and VEGF expression, and angiogenesis in vitro. PLoS ONE 7 e48393. (https:// doi.org/10.1371/journal.pone.0048393)

Michalik KM, You X, Manavski Y, Doddaballapur A, Zornig M, Braun T, John D, Ponomareva Y, Chen W, Uchida S, et al. 2014 Long noncoding RNA MALAT1 regulates endothelial cell function and vessel growth. Circulation Research 114 1389-1397. (https://doi. org/10.1161/CIRCRESAHA.114.303265)

Mishra M, Flaga J \& Kowluru RA 2016 Molecular mechanism of transcriptional regulation of matrix metalloproteinase-9 in diabetic retinopathy. Journal of Cellular Physiology 231 1709-1718. (https:// doi.org/10.1002/jcp.25268)

Misra A \& Bloomgarden Z 2018 Metabolic memory: evolving concepts. Journal of Diabetes 10 186-187. (https://doi.org/10.1111/17530407.12622)

Noren Hooten N, Martin-Montalvo A, Dluzen DF, Zhang Y, Bernier M, Zonderman AB, Becker KG, Gorospe M, De Cabo R \& Evans MK 2016 Metformin-mediated increase in DICER1 regulates microRNA expression and cellular senescence. Aging Cell 15 572-581. (https:// doi.org/10.1111/acel.12469)

Olsen AS, Sarras MP, Leontovich A \& Intine RV 2012 Heritable transmission of diabetic metabolic memory in zebrafish correlates with DNA hypomethylation and aberrant gene expression. Diabetes 61 485-491. (https://doi.org/10.2337/db11-0588)

Pan L, Lian W, Zhang X, Han S, Cao C, Li X \& Li M 2018 Human circular RNA0054633 regulates high glucoseinduced vascular endothelial cell dysfunction through the microRNA218/roundabout 1 and microRNA218/heme oxygenase 1 axes. International Journal of Molecular Medicine 42 597-606. (https://doi.org/10.3892/ ijmm.2018.3625)

Paneni F, Mocharla P, Akhmedov A, Costantino S, Osto E, Volpe M, Luscher TF \& Cosentino F 2012 Gene silencing of the mitochondrial adaptor p66(Shc) suppresses vascular hyperglycemic memory in diabetes. Circulation Research 111 278-289. (https://doi.org/10.1161/ CIRCRESAHA.112.266593)

Paneni F, Beckman JA, Creager MA \& Cosentino F 2013 Diabetes and vascular disease: pathophysiology, clinical consequences, and medical therapy: part I. European Heart Journal 34 2436-2443. (https://doi.org/10.1093/eurheartj/eht149)

Paneni F, Costantino S, Battista R, Castello L, Capretti G, Chiandotto S, Scavone G, Villano A, Pitocco D, Lanza G, et al. 2015 Adverse epigenetic signatures by histone methyltransferase Set7 contribute to vascular dysfunction in patients with type 2 diabetes mellitus. Circulation: Cardiovascular Genetics 8 150-158. (https://doi. org/10.1161/CIRCGENETICS.114.000671)

Park LK, Maione AG, Smith A, Gerami-Naini B, Iyer LK, Mooney DJ, Veves A \& Garlick JA 2014 Genome-wide DNA methylation analysis identifies a metabolic memory profile in patient-derived diabetic foot ulcer fibroblasts. Epigenetics 9 1339-1349. (https://doi.org/10.4161/15 592294.2014.967584)

Pasquier J, Hoarau-Vechot J, Fakhro K, Rafii A \& Abi Khalil C 2015 Epigenetics and cardiovascular disease in diabetes. Current Diabetes Reports 15 108. (https://doi.org/10.1007/s11892-015-0677-3)

Pirola L, Balcerczyk A, Tothill RW, Haviv I, Kaspi A, Lunke S, Ziemann M, Karagiannis T, Tonna S, Kowalczyk A, et al. 2011 Genome-wide analysis distinguishes hyperglycemia regulated epigenetic signatures of primary vascular cells. Genome Research $\mathbf{2 1}$ 1601-1615. (https://doi.org/10.1101/gr.116095.110)

Qiao Y, Zhao Y, Liu Y, Ma N, Wang C, Zou J, Liu Z, Zhou Z, Han D, He J, et al. 2016 miR-483-3p regulates hyperglycaemia-induced cardiomyocyte apoptosis in transgenic mice. Biochemical and
Biophysical Research Communications 477 541-547. (https://doi. org/10.1016/j.bbrc.2016.06.051)

Qiu GZ, Tian W, Fu HT, Li CP \& Liu B 2016 Long noncoding RNAMEG3 is involved in diabetes mellitus-related microvascular dysfunction. Biochemical and Biophysical Research Communications 471 135-141. (https://doi.org/10.1016/j.bbrc.2016.01.164)

Rana G, Donizetti A, Virelli G, Piscopo M, Viggiano E, De Luca B \& Fucci L 2012 Cortical spreading depression differentially affects lysine methylation of $\mathrm{H} 3$ histone at neuroprotective genes and retrotransposon sequences. Brain Research 1467 113-119. (https:// doi.org/10.1016/j.brainres.2012.05.043)

Ravelojaona V, Peterszegi G, Molinari J, Gesztesi JL \& Robert L 2007 Demonstration of the cytotoxic effect of advanced glycation endproducts (AGE-s). Journal de la Société de Biologie 201 185-188. (https://doi.org/10.1051/jbio:2007023)

Reddy MA, Zhang E \& Natarajan R 2015 Epigenetic mechanisms in diabetic complications and metabolic memory. Diabetologia $\mathbf{5 8}$ 443-455. (https://doi.org/10.1007/s00125-014-3462-y)

Shan K, Liu C, Liu BH, Chen X, Dong R, Liu X, Zhang YY, Liu B, Zhang SJ, Wang JJ, et al. 2017 Circular noncoding RNA HIPK3 mediates retinal vascular dysfunction in diabetes mellitus. Circulation 136 1629-1642. (https://doi.org/10.1161/CIRCULATIONAHA.117.029004)

Shang FF, Luo S, Liang X \& Xia Y 2018 Alterations of circular RNAs in hyperglycemic human endothelial cells. Biochemical and Biophysical Research Communications 499 551-555. (https://doi.org/10.1016/j. bbrc.2018.03.187)

Silambarasan M, Tan JR, Karolina DS, Armugam A, Kaur C \& Jeyaseelan K 2016 MicroRNAs in hyperglycemia induced endothelial cell dysfunction. International Journal of Molecular Sciences 17518. (https://doi.org/10.3390/ijms17040518)

Singh KK, Mantella LE, Pan Y, Quan A, Sabongui S, Sandhu P, Teoh H, Al-Omran M \& Verma S 2016 A global profile of glucose-sensitive endothelial-expressed long non-coding RNAs. Canadian Journal of Physiology and Pharmacology 94 1007-1014. (https://doi.org/10.1139/ cjpp-2015-0585)

Singh K, Pal D, Sinha M, Ghatak S, Gnyawali SC, Khanna S, Roy S \& Sen CK 2017 Epigenetic modification of MicroRNA-200b contributes to diabetic vasculopathy. Molecular Therapy 25 2689-2704. (https:// doi.org/10.1016/j.ymthe.2017.09.009)

Sommese L, Zullo A, Mancini FP, Fabbricini R, Soricelli A \& Napoli C 2017 Clinical relevance of epigenetics in the onset and management of type 2 diabetes mellitus. Epigenetics 12 401-415. (https://doi.org/1 0.1080/15592294.2016.1278097)

Stirban A, Gawlowski T \& Roden M 2014 Vascular effects of advanced glycation endproducts: clinical effects and molecular mechanisms. Molecular Metabolism 3 94-108. (https://doi.org/10.1016/j. molmet.2013.11.006)

Stoll L, Sobel J, Rodriguez-Trejo A, Guay C, Lee K, Veno MT, Kjems J, Laybutt DR \& Regazzi R 2018 Circular RNAs as novel regulators of beta-cell functions in normal and disease conditions. Molecular Metabolism 9 69-83. (https://doi.org/10.1016/j.molmet.2018.01.010)

Sun X \& Wong D 2016 Long non-coding RNA-mediated regulation of glucose homeostasis and diabetes. American Journal of Cardiovascular Disease 6 17-25.

Tabit CE, Chung WB, Hamburg NM \& Vita JA 2010 Endothelial dysfunction in diabetes mellitus: molecular mechanisms and clinical implications. Reviews in Endocrine and Metabolic Disorders 11 61-74. (https://doi.org/10.1007/s11154-010-9134-4)

Tan Q, Christiansen L, Thomassen M, Kruse TA \& Christensen KJARR 2013 Twins for epigenetic studies of human aging and development. Ageing Research Reviews 12 182-187. (https://doi.org/10.1016/j. arr.2012.06.004)

Tang Y, Jin X, Xiang Y, Chen Y, Shen CX, Zhang YC \& Li YG 2015 The IncRNA MALAT1 protects the endothelium against ox-LDL-induced dysfunction via upregulating the expression of the miR-22-3p target 
genes CXCR2 and AKT. FEBS Letters 589 3189-3196. (https://doi. org/10.1016/j.febslet.2015.08.046)

Tang N, Jiang S, Yang Y, Liu S, Ponnusamy M, Xin H \& Yu T 2018 Noncoding RNAs as therapeutic targets in atherosclerosis with diabetes mellitus. Cardiovascular Therapeutics 36 e12436. (https://doi. org/10.1111/1755-5922.12436)

Testa R, Bonfigli AR, Prattichizzo F, La Sala L, De Nigris V \& Ceriello A 2017 The 'metabolic memory' theory and the early treatment of hyperglycemia in prevention of diabetic complications. Nutrients 9 437. (https://doi.org/10.3390/nu9050437)

Tewari S, Zhong Q, Santos JM \& Kowluru RA 2012 Mitochondria DNA replication and DNA methylation in the metabolic memory associated with continued progression of diabetic retinopathy. Investigative Ophthalmology and Visual Science 53 4881-4888. (https:// doi.org/10.1167/iovs.12-9732)

Thomas AA, Feng B \& Chakrabarti S 2017 ANRIL: a regulator of VEGF in diabetic retinopathy. Investigative Ophthalmology and Visual Science $\mathbf{5 8}$ 470-480. (https://doi.org/10.1167/iovs.16-20569)

Titchenell PM \& Antonetti DA 2013 Using the past to inform the future: anti-VEGF therapy as a road map to develop novel therapies for diabetic retinopathy. Diabetes 62 1808-1815. (https://doi org/10.2337/db12-1744)

Vassy JL \& Meigs JB 2012 Is genetic testing useful to predict type 2 diabetes? Best Practice and Research: Clinical Endocrinology and Metabolism 26 189-201. (https://doi.org/10.1016/j.beem.2011.09.002)

Villeneuve LM \& Natarajan R 2010 The role of epigenetics in the pathology of diabetic complications. American Journal of Physiology: Renal Physiology 299 F14-F25. (https://doi.org/10.1152/ ajprenal.00200.2010)

Vita JA \& Keaney JF 2002 Endothelial function: a barometer for cardiovascular risk? Circulation 106 640-642. (https://doi. org/10.1161/01.cir.0000028581.07992.56)

Widlansky ME, Jensen DM, Wang J, Liu Y, Geurts AM, Kriegel AJ, Liu P, Ying R, Zhang G, Casati M, et al. 2018 miR-29 contributes to normal endothelial function and can restore it in cardiometabolic disorders. EMBO Molecular Medicine 10 e8046. (https://doi.org/10.15252/ emmm.201708046)

Witkowski M, Tabaraie T, Steffens D, Friebel J, Dorner A, Skurk C, Witkowski M, Stratmann B, Tschoepe D, Landmesser U, et al. 2018 MicroRNA-19a contributes to the epigenetic regulation of tissue factor in diabetes. Cardiovascular Diabetology 17 34. (https://doi. org/10.1186/s12933-018-0678-z)

Wold LE, Ceylan-Isik AF \& Ren J 2005 Oxidative stress and stress signaling: menace of diabetic cardiomyopathy. Acta Pharmacologica Sinica 26 908-917. (https://doi. org/10.1111/j.1745-7254.2005.00146.x)

Wu D, Hu D, Chen H, Shi G, Fetahu IS, Wu F, Rabidou K, Fang R, Tan L, Xu S, et al. 2018 Glucose-regulated phosphorylation of TET2 by AMPK reveals a pathway linking diabetes to cancer. Nature $\mathbf{5 5 9}$ 637-641. (https://doi.org/10.1038/s41586-018-0350-5)

Yamagishi SI, Nakamura N \& Matsui T 2017 Glycation and cardiovascular disease in diabetes: a perspective on the concept of metabolic memory. Journal of Diabetes 9 141-148. (https://doi. org/10.1111/1753-0407.12475)

Yan B, Yao J, Liu JY, Li XM, Wang XQ, Li YJ, Tao ZF, Song YC, Chen Q \& Jiang Q 2015 lncRNA-MIAT regulates microvascular dysfunction by functioning as a competing endogenous RNA. Circulation Research 116 1143-1156. (https://doi.org/10.1161/CIRCRESAHA.116.305510)

You L, Wang N, Yin D, Wang L, Jin F, Zhu Y, Yuan Q \& De W 2016 Downregulation of long noncoding RNA Meg3 affects insulin synthesis and secretion in mouse pancreatic beta cells. Journal of Cellular Physiology 231 852-862. (https://doi.org/10.1002/ jср.25175)

Zampetaki A, Kiechl S, Drozdov I, Willeit P, Mayr U, Prokopi M, Mayr A, Weger S, Oberhollenzer F, Bonora E, et al. 2010 Plasma microRNA profiling reveals loss of endothelial miR-126 and other microRNAs in type 2 diabetes. Circulation Research 107 810-817. (https://doi. org/10.1161/CIRCRESAHA.110.226357)

Zhang Y \& Ren J 2016 Epigenetics and obesity cardiomyopathy: from pathophysiology to prevention and management. Pharmacology and Therapeutics 161 52-66. (https://doi.org/10.1016/j. pharmthera.2016.03.005)

Zhang B, Wang D, Ji TF, Shi L \& Yu JLJO 2017a Overexpression of IncRNA ANRIL up-regulates VEGF expression and promotes angiogenesis of diabetes mellitus combined with cerebral infarction by activating NF-kB signaling pathway in a rat model. Oncotarget 8 17347-17359. (https://doi.org/10.18632/oncotarget.14468)

Zhang SJ, Chen X, Li CP, Li XM, Liu C, Liu BH, Shan K, Jiang Q, Zhao C \& Yan B $2017 b$ Identification and characterization of circular RNAs as a new class of putative biomarkers in diabetes retinopathy. Investigative Ophthalmology and Visual Science 58 6500-6509. (https:// doi.org/10.1167/iovs.17-22698)

Zhang D, Haixiang Q, Ying L, Xiangjun L, Lei Z, Dan B \& Yujun M 2018 LncRNA MEG3 overexpression inhibits the development of diabetic retinopathy by regulating TGF- $\beta 1$ and VEGF. Experimental and Therapeutic Medicine 16 2337-2342. (https://doi.org/10.3892/etm. 2018.6451)

Zhao J, Goldberg J, Bremner JD \& Vaccarino V 2012 Global DNA methylation is associated with insulin resistance: a monozygotic twin study. Diabetes 61 542-546. (https://doi.org/10.2337/db111048)

Zhao Y, Alexandrov PN, Jaber V \& Lukiw WJ 2016 Deficiency in the ubiquitin conjugating enzyme UBE2A in Alzheimer's disease (AD) is linked to deficits in a natural circular miRNA-7. Genes 7 E116. (https://doi.org/10.3390/genes7120116)

Zhong Q \& Kowluru RA 2013 Epigenetic modification of Sod2 in the development of diabetic retinopathy and in the metabolic memory: role of histone methylation. Investigative Ophthalmology and Visual Science 54 244-250. (https://doi.org/10.1167/iovs.12-10854)

Zorrilla-Zubilete MA, Yeste A, Quintana FJ, Toiber D, Mostoslavsky R \& Silberman DM 2018 Epigenetic control of early neurodegenerative events in diabetic retinopathy by the histone deacetylase SIRT6. Journal of Neurochemistry 144 128-138. (https://doi.org/10.1111/ jnc.14243)

Received in final form 20 September 2019

Accepted 10 October 2019

Accepted Preprint published online 10 October 2019 https://jme.bioscientifica.com

https://doi.org/10.1530/JME-19-0170 (c) 2019 Society for Endocrinology Published by Bioscientifica Ltd. Printed in Great Britain 